\title{
Effect of X-Ray Radiation on Electro-Optical Characteristics of CR-39 Sheets by Using Microwave and FTIR Spectroscopy Techniques
}

\author{
Hussain Ali Al-Jobouri*, Jameel M. A. Sulaiman ${ }^{* *}$ and Ahamed S. Jarallah ${ }^{* * *}$ \\ * Department of Physics, College of Science, Al-Nahrain University, Baghdad-Iraq. \\ ${ }^{* *}$ College of Dentistry, University of Mosul, Mosul-Iraq. \\ **** College of Engineering, University of Mosul, Mosul-Iraq.
}

\begin{abstract}
The effect of $\mathrm{x}$-ray radiation has been studied by measurement of the permittivity $\left(\varepsilon_{\mathrm{p}}\right)$ and transmission ratio (T\%) on CR-39 sheets a nuclear solid state track detector by microwave and Fourier Transformer Infrared)FTIR(spectroscopy techniques respectively. The permittivity $\left(\varepsilon_{\mathrm{p}}\right)$ increases with dose increase of $x$-ray radiation from 2-6.032 mGy. In addition, obtained there was dropping in the permittivity $\left(\varepsilon_{\mathrm{p}}\right)$ from the value $600 \mathrm{CV}^{-1} \mathrm{~m}^{-1}$ at the radiation dose $6.032 \mathrm{mGy}$ to the value $47 \mathrm{CV}^{-1} \mathrm{~m}^{-1}$. And there was reciprocal point at $10.5 \mathrm{mGy}$, then still $(\varepsilon \mathrm{p})$ value constant at this value with increasing of radiation dose until to $18 \mathrm{mGy}$. The absolute difference $\left(\mathrm{D}_{\mathrm{T}}\right)$ of the transmission ratio (T\%), which is measured by FTIR spectroscopy between irradiated- $\mathrm{T}_{\mathrm{R}}$ and unirradiated- $T_{0}\left[D_{R}=\left|T_{R}-T_{0}\right|\right]$ of CR-39 sheets, has been decreased at the wave number $2250 \mathrm{~cm}^{-1}$ and $2450 \mathrm{~cm}^{-1}$ to a reciprocal point of $14.0 \mathrm{mGy}$ and then increased to $18.0 \mathrm{mGy}$. This study suggest the use of CR-39 sheets as dosimeter for x-ray radiation by measuring the permittivity $\left(\varepsilon_{\mathrm{p}}\right)$ and the transmission ratio $(\mathrm{T} \%)$.
\end{abstract}

Keywords: Nuclear solid state track detector, X-ray radiation, FTIR spectroscopy.

\section{Introduction}

The influence of ionizing radiation as gamma ray on the electro-optical properties of CR-39 polymer, whose chemical formula is given in Fig.(1), has been investigated by capacitance and interferometer measurements to see the order and tendency of irradiation effects on polymer CR-39 (which is commonly used in track detectors).

Eren San, 2005 ${ }^{1}$ studied the effect of gamma radiation on the electro-optical characteristics of CR-39 material which was extensively satisfactory for some other possible uses, from carbon-implanted insulators. Experimental results show radiation -dependent degradation even at relatively low doses. Modulation of electronic properties can be exploited as an alternative diagnosis tool. CR-39 is well-known polymer which has excellent properties for various materials in detector application ${ }^{2-6}$.<smiles>C=CCOC(=O)OCCOC(=O)OCC=C</smiles>

Fig.(1) Chemical formula of CR-39 polymer chemically poly allyl diglycol carbonate monomer is an ester formed by transesterification of diallyl carbonate within diethylene glycol ${ }^{1}$.

The permittivity $\left(\varepsilon_{\mathrm{p}}\right)$ and dielectric loss factor have been measured in the frequency range $50-10^{5} \mathrm{~Hz}$ for the solid track detector CR-39 irradiated with gamma ray dose at the range 5-100 $\mathrm{kGy}^{7}$. The variation of $\varepsilon_{\mathrm{p}}$ with gamma dose have been interpreted in terms of structural changes as emphasized from infrared spectra.

A mathematical model has been introduced describing the use of CR-39 as a dielectric dosimeter $^{7}$. The effect of gamma radiation on etching characteristic of some solid state track recorders, viz CR-39 plastic, glass and phlogopite mica preexposed to $252{ }^{\circ} \mathrm{C}$ 
fission fragments are irradiated with gamma radiation dose varying from $50 \mathrm{krad}$ to $50 \mathrm{Mrad}$ in order to study the effect of gamma irradiation on etching characteristics of these detector. It has been found that all these detectors are dose rate dependent. CR-39 is found to be more sensitive to gamma rays than any other solid ${ }^{8}$.

Optical absorption of CR-39 is influenced by the irradiation dose while, for SR-90, it is found to be an inverse function of higher doses $^{9}$. Systematic studies have been made concerning the effects of gamma dose on the track registration properties of solid-state track detector (SSTD). The changes in bulk and track etch rates in CR-39 plastics as well as insensitivity due gamma rays in the dose range of $0-10^{3} \mathrm{kGy}$ at different temperatures 338-353 ${ }^{\circ} \mathrm{K}$, discussed on the basis of degradation and cross-linking mechanisms, have been studied by Surinder Singh and Neerija $^{10}$. Various studies have been made to determine the response of solid state track detectors like Lexan polymer to gamma irradiations.

In 2007 Neerja S. P. and Surinder S. ${ }^{11}$ studied the activation energy associated with track and bulk etch rates at a given temperature and found that the activation energy decreases with gamma-dose. $\mathrm{Zaki}^{12}$ studied gamma-induced modification on optical band gap of CR-39 as a solid state nuclear track detector (SSNTD), although the effect of gamma irradiation on optical absorption of nuclear track detectors CR-39 was studied in different absorbed doses using Ultraviolet-visible UV-VIS spectroscopy. The present study used CR-39 as a dosimeter for ionizing radiation by measuring the permittivity $\left(\varepsilon_{\mathrm{p}}\right)$ and transmission ratio $(\mathrm{T} \%)$.

\section{Materials and Methods}

Ten measurement samples of CR-39 sheet were purchased from China, Changzhou Welding Co., each sample has a thickness of $1.2 \mathrm{~mm}$ and $16 \times 12 \mathrm{~mm}$. The permittivity values were determined by measuring* the quality factor and dielectric material properties as a microwave technique ${ }^{13}$. Measurements were carried out at $8 \mathrm{GHz}$ spot frequency.

\footnotetext{
* The measurements was recorded in the laboratory of the College of Engineering University of Mosul.
}

Furthermore spectroscopic analysis was performed with FTIR spectrophotometer bruker tensor-27 at wave number range 1800$2600 \mathrm{~cm}^{-1}$. The above mentioned samples were exposed to radiation doses from x-ray generated at $70 \mathrm{kV}$ and $100 \mathrm{~mA}$. X-ray radiation dosimetry was performed using densitometer model DT1105 with Kodak Dental Film -Data Sheet, 2002.

\section{Results and Discussions}

Fig.(2) shows the effect of x-ray radiation on CR-39 sheets as obtained in this study by measuring the permittivity $\left(\varepsilon_{\mathrm{p}}\right)$ values. There is an increase in $\left(\varepsilon_{\mathrm{p}}\right)$ from $100 \mathrm{CV}^{-1} \mathrm{~m}^{-1}$ to $600 \mathrm{CV}^{-1} \mathrm{~m}^{-1}$ with radiation dose in the range of $2-6.032 \mathrm{mGy}$. A drop in the permittivity after the radiation dose $6.032 \mathrm{mGy}$ from the value $600 \mathrm{CV}^{-1} \mathrm{~m}^{-1}$ to $47 \mathrm{CV}^{-1} \mathrm{~m}^{-1}$ ending in the radiation dose of $10.5 \mathrm{mGy}$ which represent a reciprocal point of $\varepsilon_{\mathrm{p}}$ at this dose is noticed. After radiation dose of $12.08 \mathrm{mGy}$, the $\left(\varepsilon_{\mathrm{p}}\right)$ value stays constant with increasing radiation dose.

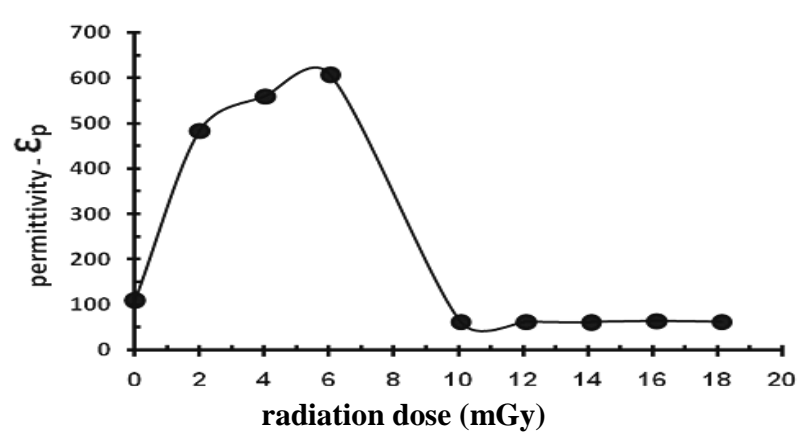

\section{Fig.(2) Permittivity ( $\left.\varepsilon_{p}\right) C V^{-1} m^{-1}$ of CR-39 sheets measured by microwave technique with $x$-ray radiation dose range 0-18.128 mGy.}

The decrease of $\varepsilon_{\mathrm{p}}$, shown in Fig.(2), is similar to the results found by Eren. San, $2005^{(1)}$ between the capacitance-Cp and gamma radiation dose where he obtained two reciprocal points at $20 \mathrm{kGy}$ and $60 \mathrm{kGy}$ for CR-39 sheets with a thickness of $760 \mathrm{~mm}$. The capacitance of capacitor depends on the permittivity $\left(\varepsilon_{\mathrm{p}}\right)$ of the dielectric layer by the following equation ${ }^{15}$.

$\mathrm{C}_{\mathrm{p}}=\varepsilon_{\mathrm{p}}(A / d)$ 


\section{Science}

where $\mathrm{C}_{\mathrm{p}}$ is capacitance, $\varepsilon_{\mathrm{p}}$ is permittivity, $A$ is the area of plate capacitance, and $d$ is the separation distance between the two conductive plates.

The drop in magnitude of $\varepsilon_{\mathrm{p}}$ from its maximum value, in this study, was $70 \%$ which is comparable to the drop in magnitude of $\mathrm{Cp}\left(65 \%\right.$ at the Eren $\mathrm{San}^{(1)}$ study is reported). The drop in the magnitude of $\varepsilon_{\mathrm{p}}$ which appear as a result of broken bonds for the CR-39 structure Fig.(1) as shown in other studies $^{(14)}$.

The relation between $\varepsilon_{\mathrm{p}}$ and radiation dose at the range 2-6.032 $\mathrm{mGy}$ which is shown in Fig.(2) has been plotted $\varepsilon_{\mathrm{p}}$ in Fig.(3). A linear behavior can be attributed to the experimental values and a fit is applied as indicated by the inset equation.

Dose $(\mathrm{mGy})=0.032 \varepsilon_{\mathrm{p}}-13.65$

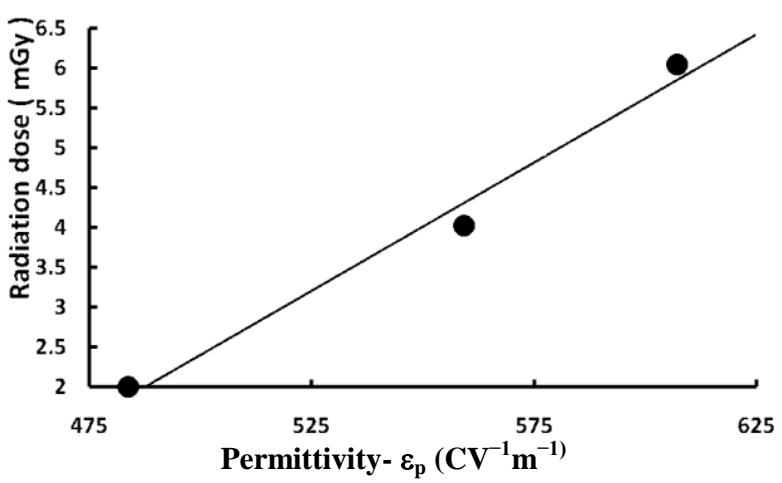

Fig.(3) Permittivity ( $\varepsilon_{p}$ ) in $\mathrm{CV}^{-1} \mathrm{~m}^{-1}$ of CR-39 sheets and radiation dose in the range 2 - $6.032 m G y$.

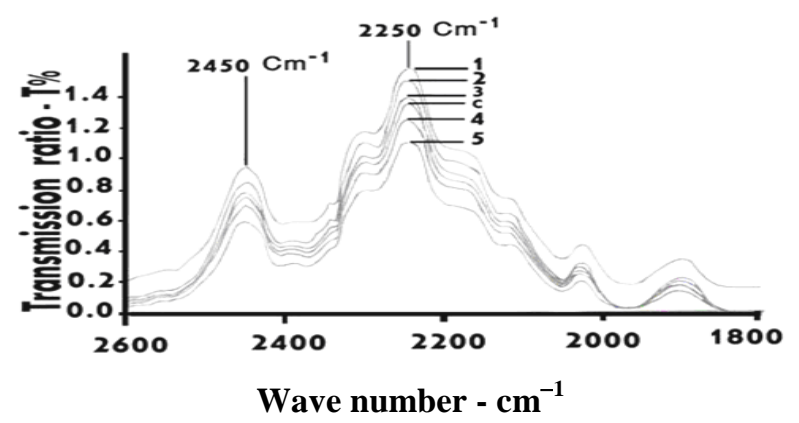

Fig.(4) FTIR Spectrum at the wave number range $1800-2600 \mathrm{~cm}^{-1}$ for which irradiated

CR-39 sheet samples 1, 2, 3, C, 4, 5. mentioned in (Table (1)) in range of radiation dose 10.064 - $18.128 \mathrm{mGy}$.
Table (1)

Transmission Ratio (T\%) at wave numbers $2250 \mathrm{~cm}^{-1}$ and $2450 \mathrm{~cm}^{-1}$ for $C R-39$ sheets irradiated with $x$-ray radiation dose range from 10.064 to $18.128 \mathrm{mGy}$.

\begin{tabular}{|c||c||c||c|}
\hline \multirow{2}{*}{$\begin{array}{c}\text { Sample } \\
\text { number }\end{array}$} & \multirow{2}{*}{$\begin{array}{c}\text { Radiation } \\
\text { Dose }(\mathbf{m G y})\end{array}$} & \multicolumn{2}{|c|}{$\begin{array}{c}\text { Transmission Ratio(T\%) } \\
\text { at wave number }\end{array}$} \\
\cline { 3 - 4 } & & $\mathbf{2 2 5 0 \mathbf { c m } ^ { - 1 }}$ & $\mathbf{2 4 5 0} \mathbf{c m}^{-\mathbf{1}}$ \\
\hline 1 & 10.064 & 154 & 0.95 \\
2 & 12.080 & 147 & 0.84 \\
3 & 14.000 & 138 & 0.77 \\
$\mathrm{C}$ & 0 & 135 & 0.75 \\
4 & 16.112 & 125 & 0.68 \\
5 & 18.128 & 11 & 0.59 \\
\hline
\end{tabular}

Fig.(4) displays the variable change in FTIR spectrum at wave number range 2600$1800 \mathrm{~cm}^{-1}$ for the irradiated CR-39 sheets at the range of $10.064-18.128 \mathrm{mGy}$. A decrease in transmission ratio (T\%) of FTIR spectrum with increase of radiation dose on CR-39 is observed, which obtained also in the maximum change in transmission ratio (T\%) happened at the wave number 2547.83$2409.38 \mathrm{~cm}^{-1}$ and $2340.31-2194.59 \mathrm{~cm}^{-1}$.

The absolute difference of the transmission ratio (T\%), which is measured by FTIR spectroscopy between irradiated- $T_{R}$ and unirradiated $-\mathrm{T}_{0}$ of CR-39 sheets $\left[\mathrm{D}_{\mathrm{R}}=\Delta \mathrm{T} \%\right.$ $\left.=\left|\mathrm{T}_{0} \%-\mathrm{T}_{\mathrm{R}} \%\right|=\left|\mathrm{T}_{0}-\mathrm{T}_{\mathrm{R}}\right|\right]$ decreases at the wave number $2250 \mathrm{~cm}^{-1}$ and $2450 \mathrm{Cm}^{-1}$ at the reciprocal point $14.0 \mathrm{mGy}$ as shown in Fig.(5). After this point, $D_{R}$ increases with increasing radiation dose until $18.123 \mathrm{mGy}$. 


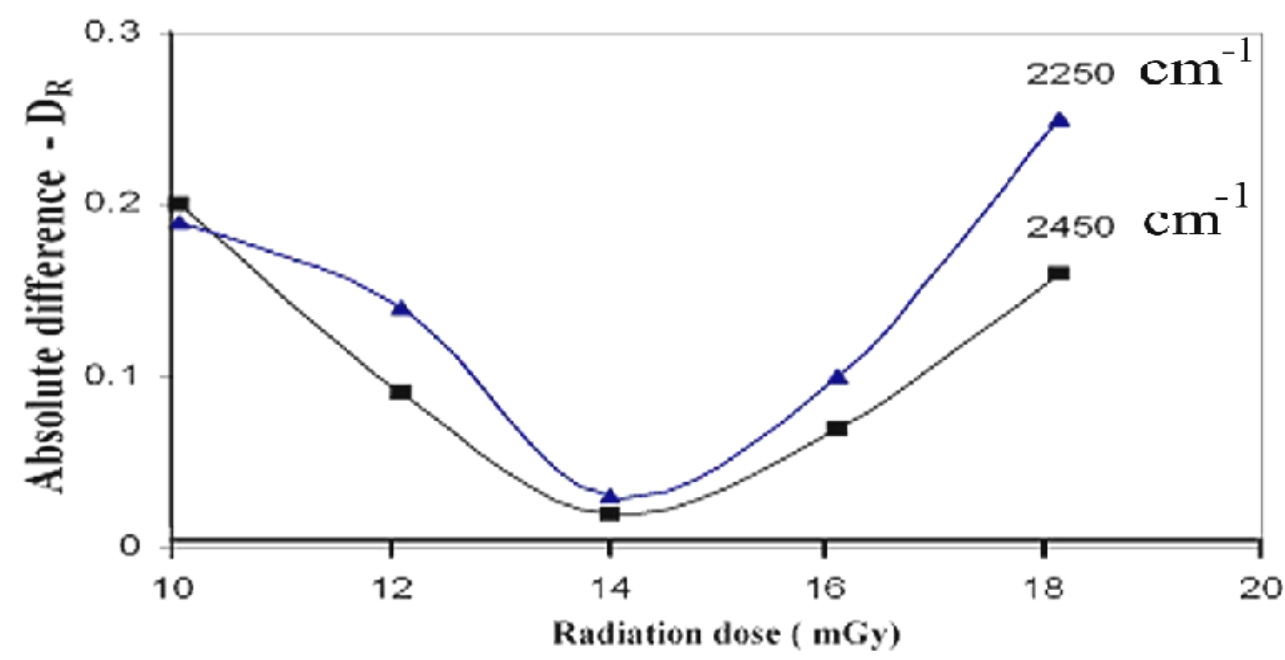

Fig.(5) Absolute difference $\left(D_{R}\right)$ of the transmission ratio (T\%) between irradiated-T $T_{R}$ and un-irradiated $-T_{0}$ of CR-39 sheets at the wave number 2250 and $2450 \mathrm{~cm}^{-1}$ with the radiation dose ( $m G y)$.
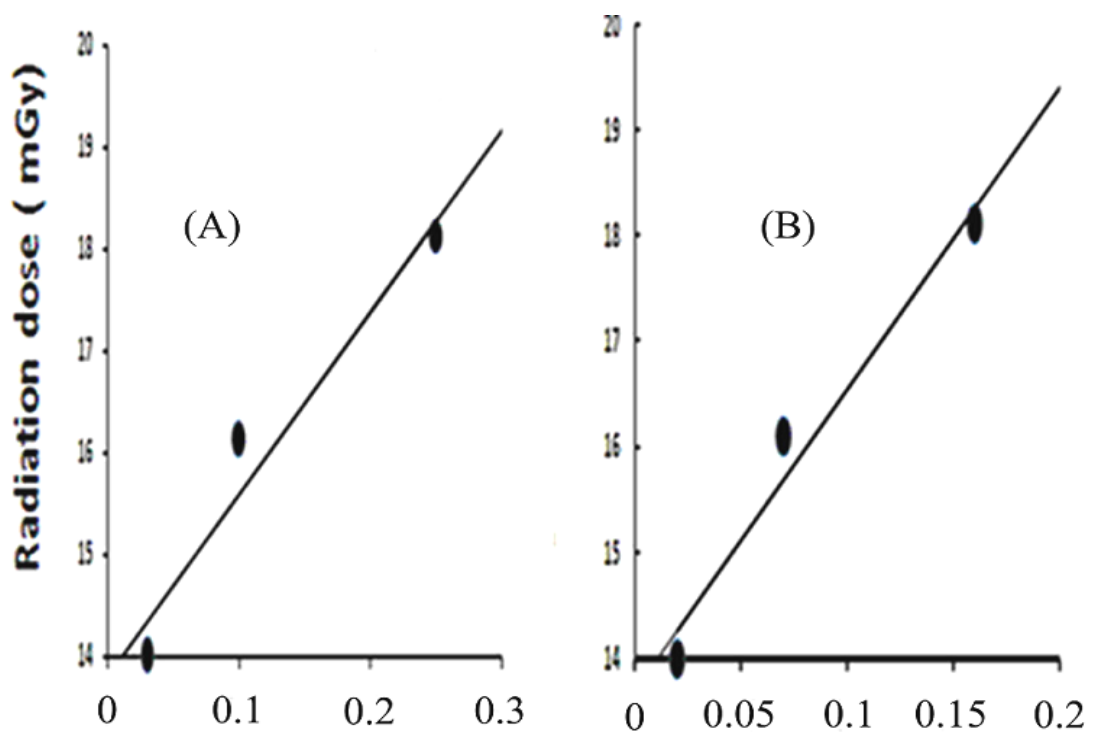

Absolute difference $-D_{R}$

Absolute difference $-D_{R}$

Fig.(6) Absolute difference $\left(D_{R}\right)^{*}$ for irradiated CR-39 sheets with range radiation dose $14-20 \mathrm{mGy}$ at the wave numbers $2245 \mathrm{~cm}^{-1}(A)$ and $2450 \mathrm{~cm}^{-1}(B)$ with linear equation 4 and equation 5 respectively.

${ }^{*}\left[D_{R}=\Delta T \%=\left|T_{0} \%-T_{R} \%\right|=\left|T_{0}-T_{R}\right|\right]$, where $T_{0}:$ transmission ratio-T\% for un-irradiated CR-39, $T_{R}:$ transmission ratio-T\% for irradiated CR-39. 


\section{Science}

The behavior of absolute difference $\left(D_{R}\right)$ with radiation dose as straight line is seen in equation (3) and (4) for the wave number $2250 \mathrm{~cm}^{-1}$ and $2450 \mathrm{~cm}^{-1}$ respectively and shown in Fig.(6).

Dose $(\mathrm{mGy})=17.92 \mathrm{D}_{\mathrm{R}}+13.81$,

for $2250 \mathrm{~cm}^{-1}$
Dose $(m G y)=28.64 D_{R}+13.69$,

for $2450 \mathrm{~cm}^{-1}$

Table (2) shows the radiation dose range of the response of CR-39 which is calculated by measuring $\varepsilon_{\mathrm{p}}$ and transmission-T\% by using microwave and FTIR spectroscopy techniques respectively.

Table (2)

Radiation dose ranges and equations calculated by measuring permittivity $\left(\varepsilon_{p}\right)$ and absolute difference $\left(D_{R}\right)$ for CR-39 sheets with reciprocal point using microwave and FTIR spectroscopy techniques respectively.

\begin{tabular}{||c|c|c||c||c|}
\hline $\begin{array}{c}\text { Radiation dose } \\
\text { range }(\boldsymbol{m G y})\end{array}$ & Equation calculated & $\begin{array}{c}\text { Reciprocal } \\
\text { Point }(\mathbf{m G y})\end{array}$ & $\begin{array}{c}\text { Measuring } \\
\text { parameter }\end{array}$ & Technique \\
\hline \hline $2-6$ & Dose $(\mathrm{mGy})=0.032 \varepsilon_{\mathrm{p}}-13.65$ & 10.5 & $\varepsilon_{\mathrm{p}}$ & microwave \\
\hline \hline $14-18$ & $\begin{array}{c}\text { Dose }(\mathrm{mGy})=17.92 \mathrm{D}_{\mathrm{R}}+13.81 \\
\text { at } 2250 \mathrm{Cm}^{-1}\end{array}$ & 14 & $\mathrm{D}_{\mathrm{R}}$ & $\begin{array}{c}\text { FTIR } \\
\text { spectroscopy }\end{array}$ \\
\hline & $\begin{array}{c}\text { Dose }\left(\mathrm{mGy}^{\mathrm{G}}=28.64 \mathrm{D}_{\mathrm{R}}+13.69\right. \\
\text { at } 2450 \mathrm{Cm}^{-1}\end{array}$ & 14 & \\
\hline
\end{tabular}

This present study uses CR-39 sheets as the radiation dosimeter for $\mathrm{X}$-ray radiation for two ranges of radiation doses. The first is for low dose range $(2-6 \mathrm{mGy})$ by using microwave technique from measuring permittivity $\left(\varepsilon_{\mathrm{p}}\right)$, and the second is for the high dose range (14-18 mGy) by using FTIR spectroscopy technique from measuring $D_{R}$ as shown in Table 2. The reciprocal points at 10.5 mGy and 14.0 mGy (Table (2)) for microwave and FTIR spectroscopy respectively which determined in this study, were less the that values appeared in Eren San (2005) study at $20 \mathrm{mGy}$ and $60 \mathrm{mGy}$.

This deviation in the reciprocal points for the radiation dose in this study, although large, but is arranged in the same order comparable with Eren San(2005). The difference of thickness of CR-39 sheetsmay be responsible for such deviation.

\section{References}

[1] Eren San, S., "The influence of gamma radiation on the electro-optical characteristics of CR-39 polymer", J. Radiol. Prot. 25, 93-96, 2005.

[2] Vareille, J. C., Decossas, J. L., Sadaka, S. and Teyssier, J. L., "CR 39 used as a detector in a neutron dosimeter Polymer", Nucl. Instrum. Methods phys., Res. B 17, 280-284, 1986.

[3] Zapparoil, G. Tommasino, L. Djeffal, S. and Maiorana, A., "Additional results with electrochemically etched CR 39 neutron dosemeters", Int. J. Radiat. Appl. Instrum., D 12, 675-678, 1986.

[4] Ralarosy, J. Debeauvais, M. Adloff, J. C., Zamani, M., Femandez, F., Jokic, S. and Todorovic, Z., "Interpretation of the 3-pronged events from the ${ }^{238} \mathrm{U}+\mathrm{Au}$ reaction registered within CR 39 solid state nuclear track detectors", Int. J, Radiat. Appl. Instrum, D 19, 651, 1991. 
[5] Barillion, R. Klein, D., Chambaudet, A., Membrey, F. and Formm, M., "Additional uses of polymeric nuclear track detectors (CR 39 and LR 115) for measuring radon emanation", Int. J. Radiat. Appl. Instrum. D 19, 291, 1991.

[6] Bordy, J. M., Medioni, R. and portal, G., "Spectrophotometric measurement of track density in CR39 for high neutron dose determinations", Int. J. Radiat. Appl. Instrum. D, 241-244, 1991.

[7] M. EL-Shahawy, A. Hussein, "CR-39 as a gamma dosimeter: dielectric and infrared studies", Journal of materials science 27, 6605-6608, 1992.

[8] Surinder Singh, Balwinder Singh, "The effect of gamma radiation on etching characteristic of some solid state track recorders", Tracks and Radiation Measurements, Vol. 15, issues 1-4, 199202, 1992.

[9] Saad, A. F., Atwa, S. T., Yokota, R. and Fujiii, M., November, "Radiation-induced Modifications on spectroscopic and thermal properties of CR-39 and SR-90 nuclear track detectors", Radiation measurements, Vol.40. Issues 2-6, 780-784, 2005.

[10] Surinder Singh, Neerja, "The effect of gamma-irradiation on the activation energy of bulk and track etching in CR-39 plastic track detector", Radmeas. J. radmeas., doi: 10.1016, 09.007, 2007.

[11]Neerija, Sangeeta Prasher, Surinder Singh, "The effect of gamma irradiation on the activation energy of bulk and track etching in Lexan track detector", Radiation Measurement, Vol. 42. Issue 9, October, 1507-1509, 2007.

[12] M.F.Zaki, "Gamma-induced modification on optical band gap of CR-39 SSNTD", Braz. J. Phys. Vol.38. No.4. Sapaulo, 2008.

[13]Lance, A.L., "Introduction to microwave theory and measurements", McGraw-Hill (New York) 1964.

[14]S. A. Nouh, "Physical changes associated with gamma doses of PM- 555 solid-state nuclear track detector, Radiation
Measurements", Vol.38, Issue 2, 167-172, 2004.

[15] John W. Mc Farland Capacitors, Dielectrics and Induced Charge, March 8, Physics 122L-01, 2005.

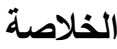

نم دراسة تأثثر الأشعة السينية على شرائح CR-39

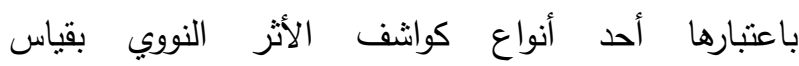
الممانعة. المايكروية ومطيافية - FTIR على التوالي. تنين ازدياد قيمة

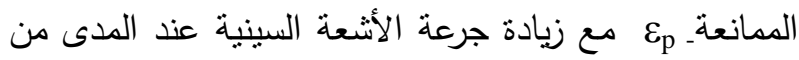
6.032 mGy بالإضافة إلى ذلك لوحظ 2 mGy هبوط في قيمة - ع ع عد الجرعة 6.032 من قيمة الممانعة 600 إلى $47 \mathrm{CV}^{-1} \mathrm{CV}^{-1} \mathrm{~m}^{-1}$ وهناك فئك انقلابية حصلت عند الجرعة 10.5 mGy، وبعدها تستقر قيمة. ع ع بقيمة ثابتة مع زيادة الجرعة الإثعاعية حتى الجرعة 18 mGy 18 وجد ان صافي التفاذية

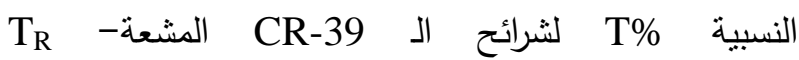
وغير المشعة- $\left(D_{R}=\Delta\left|T_{R}-T_{0}\right|\right) ، T_{0}$

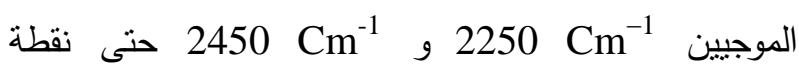
الأنقلابية 14.0 mGy، وبعدها تزداد حتى الجرعة 18.0 mGy هذه الدراسة تبين إمكانية استخدام شرائح الـ

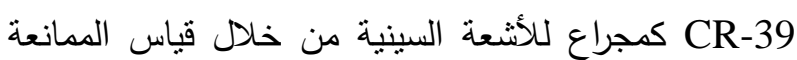

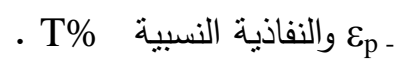

